\title{
Comparing analysis methods in assessing dynamic dual bolus cardiac magnetic resonance perfusion flow
}

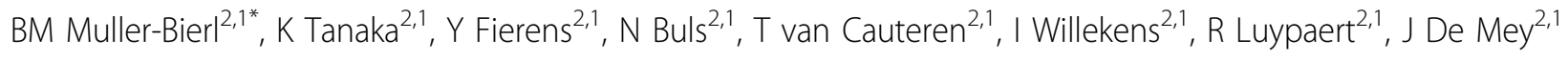

From 16th Annual SCMR Scientific Sessions

San Francisco, CA, USA. 31 January - 3 February 2013

\section{Background}

We compare eight reported methods (1-8) for the analysis of cardiac perfusion flow in 3 Tesla MRI on a porcine model. Therefore, an anaesthetized healthy minipig was repeatedly scanned (x5) with a 14 day interval with Turbo FLASH at $3 \mathrm{~T}$. The data obtained from the images consists of the temporal course of the arterial input function (AIF) and of the tissue response function (TRF). We compared 8 analysis methods by statistical evaluation of determined perfusion flow. The analysis methods investigated were Fermi function (1), Modelfree Deconvolution (2), Modified Tofts (3), Exchange (4), Uptake (5), Tofts (6), Patlak (7), and Maximum Slope (8).

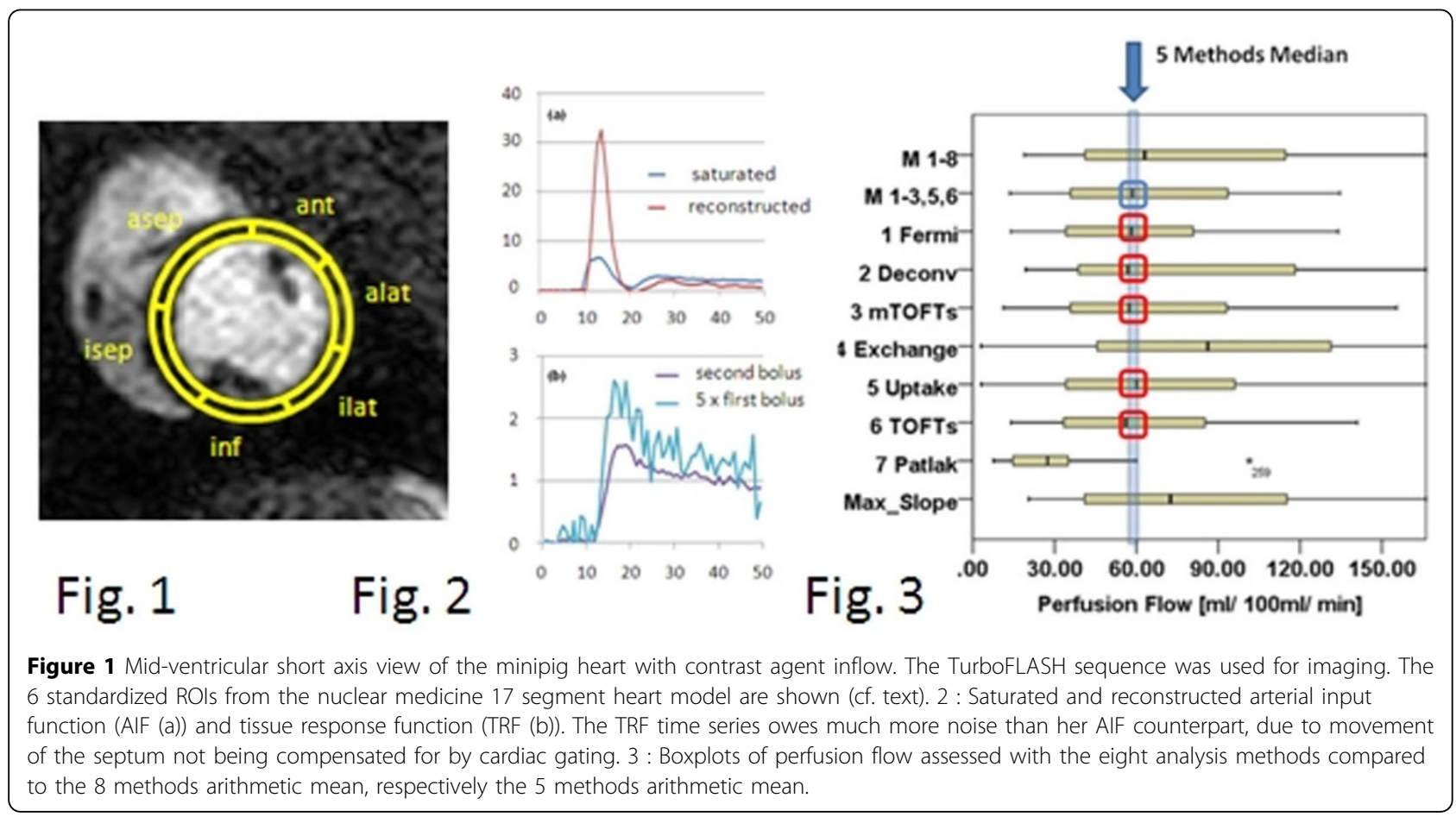

${ }^{2}$ Radiology, Flemish University Hospital Brussels, Brussels, Belgium
Full list of author information is available at the end of the article 


\section{Methods}

We compared the analysis methods by correlation analysis, by comparing the medians of the measured flow values, by regression analysis, by Bland-Altman analysis, and by related samples Wilcoxon rank test. We also investigated numerically the throughput of noise in the TRF on the analysis methods 1-4.

\section{Results}

Five methods (Fermi, Deconvolution, the Tofts methods, and Uptake) were found to be suitable for normal perfusion flow evaluation. Repeatability of the results - independent on the analysis methods - was bad, which is due to the movement of the septum. For measuring stress perfusion, numerical modeling shows that using the Fermi and modified Tofts methods results in large bias errors in the presence of noise in the TRF.

\section{Conclusions}

As long as there is noise present in the TRF due to the moving septum, the evaluation of perfusion flow is not possible. We expect that measurement of cardiac perfusion flow will be possible using the Turbo FLASH sequence and the theoretical frameworks for perfusion flow analysis using the dual bolus method. Based on our investigation so far, we claim that Fermi, Model-Free Deconvolution, Uptake and the Tofts methods are all suitable for normal perfusion flow evaluation. Evaluation of the TRF in heart has to use spatial registration and correction: To establish a reliable procedure to assess the perfusion value based on the dual bolus data, motion correction of the septum by spatial image reconstruction is mandatory and should be the next logical step.

\section{Funding}

The work was payed by the Department of Radiology of the Flemish University Hospital Brussels.

\footnotetext{
Author details

${ }^{1}$ Radiology, Flemish University Hospital Brussels, Brussels, Belgium.

${ }^{2}$ Radiology, Flemish University Hospital Brussels, Brussels, Belgium.
}

Published: 30 January 2013

doi:10.1186/1532-429X-15-S1-W38

Cite this article as: Muller-Bierl et al:: Comparing analysis methods in assessing dynamic dual bolus cardiac magnetic resonance perfusion flow. Journal of Cardiovascular Magnetic Resonance 2013 15(Suppl 1):W38.
Submit your next manuscript to BioMed Central and take full advantage of:

- Convenient online submission

- Thorough peer review

- No space constraints or color figure charges

- Immediate publication on acceptance

- Inclusion in PubMed, CAS, Scopus and Google Scholar

- Research which is freely available for redistribution

Submit your manuscript at www.biomedcentral.com/submit 